\section{Abstractions}

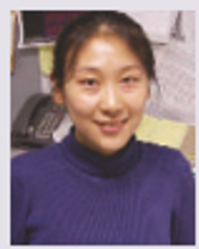

\section{FIRST AUTHOR}

The paper on page 88 is a landmark for Ze 'Ginger' Cheng: she has never before been a 'first author' in Nature. A computer programmer and database administrator at the University of Washington's Department of Genome Sciences, Cheng spent most of the past year fur io usly writing computer code. The fruit of her labour is an analysis of DNA duplication differences between human and chimp.

Cheng was looking for duplications of DNA that appear in both genomes, as well as those that are unique to either species. She was also seeking duplications with a differentnumber of copies in humans and chimps. Such duplications are thought to be aforce for evolutionary change in genomes and aresometimes related to human diseases. Nature caught up with Cheng to find out more about her work.

How massive was this project? It was big. I worked eight or nine hours a day on this for a year. Ihelped analyse around 100 gigabytes of data. For onetable, I looked at 700 files. The project has been the dominant thing in my life for ayear. It has been my life for ayear.

What sort of challenges did you face? Wehada very heated lab meeting about the critical thresholds todetect recent duplications using data from two different species.

Why was this a challenge for you? My background is in cell biology and molecular biology. Genomics research is very different. I had to read some papers to learn the concepts and to get used to what everybody was talking about.

Whatdid the othermembers of the group do? Evan Eichler came up with all the analys is for the paper and set out the way we should approach thetopic. Eray Tuzun performed the analysis for duplication in the chimp genome assembly. XinweiShe did the geneexpression analys is of duplicategenes using datafrom our collaborator, Svante Pagbo.

Any critical points?

There was one day when I was very ill, but I had to fin ish what I was working on. I like my job, but it involves pressures. If you don't conquer those pressures, you don't accomplish anything.

How did you deal with the stress? Ijog to shed the pressure. When I get mentally exhausted, I want to be physically exhausted to relax.

How do you feel about the paper now? I was not very clear of the big picture at the beginning. But when I look back, it is so beautiful.

\section{MAKING THE PAPER}

Sally McBrearty and

Nina Jablonski

\section{How a trip to Kenya put the modern chimpanzee on the map.}

Examining a fossilized molar in Nairobi last October, Nina Jablonski was thinking just one thing: "This is no monkey." It should have been. After all, Jablonski, an anthropologist at the California Academy of Sciences, was in the Kenyan capital to study a collection of monkey fossils unearthed at the Kapthurin Formation in the East African Rift Valley.

But the size and shape of the tooth were wrong. "My first thought was, 'Oh my gosh, this is a gibbon," Jablonski says. "Then I realized, no, it was almost certainly a chimp." Further searching among the monkey fossils turned up a second anomaly; this time, an incisor.

The collection had been amassed by Sally McBrearty, an anthropologist at the University of Connecticut, and her team who were in Kenya looking for stone tools and fossils. Jablonski's musings echoed McBrearty's suspicions. "I Ibelieved it was an ape," McBrearty recalls. The result was the paper co-authored by the pair on page 105 of this issue.

"I'm going back
to monkeys - but
I cer tainly won't
ignore any chimps
that cross my trail."
- Nina Jablonski

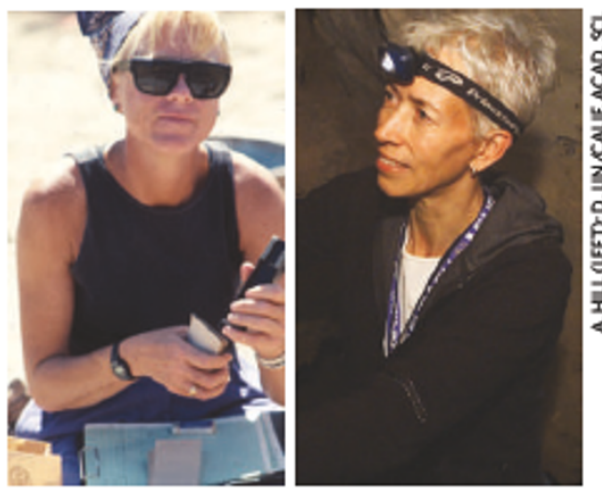

Sally McBrearty (left) and Nina Jablonski.

of the body and less likely to be crushed or decay. "I'm hoping to go back and spend more time looking for the rest of this creature," says McBrearty.

The discovery of the chimp teeth was a major surprise, Jablonski says. No fossils of modern apes had ever been found in Africa and to cap it all, the remains came from the Rift Valley. Today, chimps are found only in western and central Africa; the Rift Valley was seen as a geographical barrier to the species, preventing its spread farther east. But the teeth, which are about 500,000 years old, put chimps in a part of the continent

Jablonski compared the fossils with teeth of modern chimps at the National Museums of Kenya. The molar, with its distinctive crown features, was a perfect match. "I sent off a very excited e-mail to Sally, Jablonski says. "She was thrilled because she had suspected that the teeth did not belong to a monkey."

McBrearty immediately sent her team back into the field. By March, the researchers had found more chimp teeth, bringing the total to four, three of which are described in this issue.

${ }^{\alpha}$ This is the first unequivocal example of a modern chimpanzee in the fossil record - no question," Jablonski says.

McBrearty's team has yet to uncover any other chimp remains. Teeth are often the only fossils left, as they are harder than other parts where they weren't known to exist. And, more importantly, they put the chimps side-by-side with a hominid.

Although she is aware of implications for evolution and anthropology, Jablonski sees some irony in the discovery of the teeth. She has been working on monkey fossils for $\mathbf{3 0}$ years, and has made many finds that characterize that group's evolution, but few people outside her speciality "gave a hoot or a holler" about such work. The chimp teeth attracted much more attention because of the dose evolutionary link between the apes and humans.

Jablonski has now returned to her primary research interest. "I'm happily going back to monkeys," she says. "But I certainly won't ignore any chimps that cross my trail.

\title{
QUANTIFIED GERMANY
}

\section{A numerical pers pective on Nature authors.}

Several authors in Germany present research in Nature this week. Andreas Richter and his team, working in Bremen and Hamburg, use satellite data to measure levels of nitrogen dioxide in the lower atmosphere and report a worrying increase in nitrogen oxide emissions over industrial areas of China (see page 129).

Thomas Blankenstein and Gerald Willimsky, at the Charité in Berlin, use mice to look at cancer immunology and show how sometimes certain types of tumour canevade an immune response (see page 141).

And Svante Pagabo, based in Leipzig is a member of the team reporting results of a genome-wide comparison of DNA similarities between humans and chimpanzees (seepage 88).
537 submissions to Nature have come from Germany since 1January 2005 (totalglobal submissions $=8,987$ )

269 authors published in Natureso far this year were working in Germany (total number of published authors $=3,725$ )

22 authors working in Germany have had more thanone paper published in Nature since 1 January 2005.

8 authors working in Germany are presenting original research in Nature this week. 